\title{
Simulating Contaminant Attenuation, Double-Porosity Exchange, and Water Age in Aquifers using MOC3D
}

MOC3D is a general-purpose computer model developed by the U.S. Geological Survey (USGS) for simulation of three-dimensional solute transport in ground water (Konikow and others, 1996). The model is an update to the widely used USGS two-dimensional solutetransport model (MOC) and is implemented as an optional "package" for the ground-water flow model MODFLOW (Harbaugh and McDonald, 1996). Directly coupling the timetested MOC transport algorithms with the widely used MODFLOW program makes MOC3D a powerful tool for simulation of solute transport in ground water in many hydrogeologic settings. The model simulates transport processes that include:

* Advection - Transport of dissolved solutes at the same rate as the average groundwater flow velocity.

$\rightarrow$ Diffusion - Spreading of solute from areas of high concentration to areas of low concentration, caused by "random" molecular motion.

\&ispersion - Diffusion-like spreading of solute that is caused primarily by spatial variability in aquifer properties, which results in spatial variability in transport velocity.

* Retardation - Reduction in the apparent solute velocity, compared to the groundwater velocity, caused by linear equilibrium sorption on aquifer materials.

* Decay - Disappearance of solute caused by reactions such as radioactive decay or biodegradation that are proportional to concentration.

* Growth - Creation (or disappearance) of solute mass caused by reactions that proceed independent of the solute concentration, such as some cases of biodegradation.

\& Double-porosity exchange - rate-limited exchange of solute mass between mobile and immobile zones; for example, between fractures and the rock matrix.

MOC3D also accounts for solute sources and sinks associated with a wide range of water sources and sinks. This fact sheet highlights recent extensions to MOC3D (Goode, 1999) for simulation of contaminant attenuation, double-porosity exchange, and water age and provides information on obtaining programs and documentation.

\section{MOC3D - A General-PURPOSE SOlUte-Transport MODEL}

MOC3D is an optional package of the USGS finite-difference groundwater flow model (MODFLOW) that solves the solute-transport equation. MODFLOW provides the needed ground-water fluxes and water sink and source rates. In addition to the hydraulic properties required for the flow model, MOC3D requires the user to specify porosity, model-layer thicknesses, initial concentrations, and concentrations in water sources. Diffusion, dispersion, first-order decay, zero-order growth, and retardation can optionally be included. A method-of-characteristics numerical scheme is used in MOC3D that is well suited for advection-dominated transport problems. Such problems are characterized by small dispersivities relative to the plume size, which is typical of many field problems. A recent extension of MOC3D appreciably reduces the computer time required for dispersion-dominated problems (Kipp and others, 1998).

Application of MOC3D is the third step in a logical sequence of (1) flow, (2) advective-transport, and (3) solute-transport simulation (fig. 1). After a flow model is constructed, advective transport can be efficiently examined

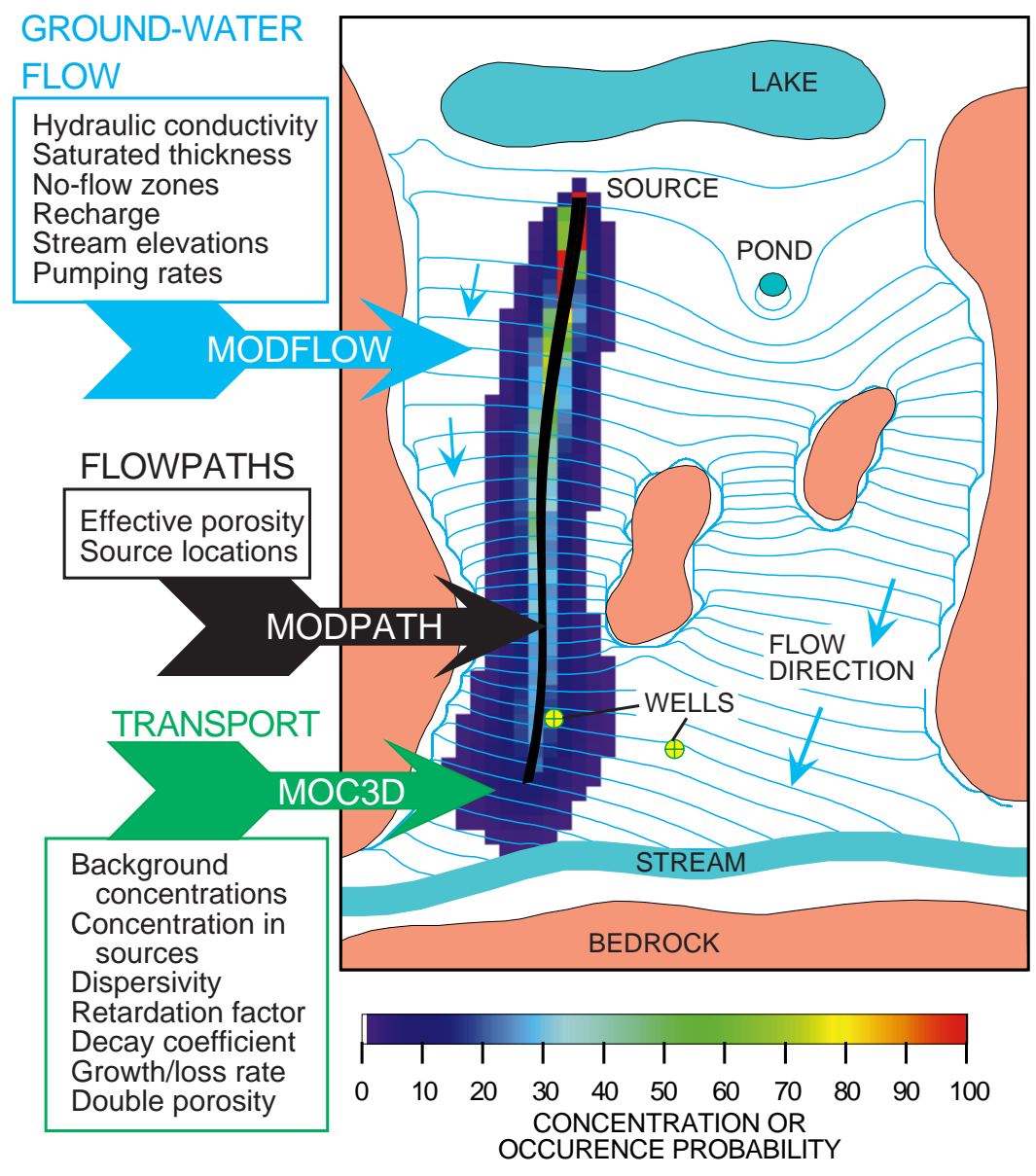

Figure 1. Typical input and illustration of output for simulation of ground-water flow and solute transport using MODFLOW, MODPATH, and MOC3D. 
by particle tracking using MODPATH (Pollock, 1994). If traveltime results are needed, effective porosity must be specified. Concentrations in the aquifer and in discharges, such as pumping wells, as a result of advection and dilution (mixing) can be simulated by use of MOC3D and specified initial and source concentrations. Optional input on dispersion and reactions allows effects of these processes to be simulated.

Simulation of solute transport with dispersion using MOC3D also can enhance particle-tracking analyses by approximating uncertainty in sourcearea delineation and potential contamination advection. For example, figure 1 shows nine closely spaced pathlines of ground-water flow from a continuous source of contamination after 20 years calculated using MODFLOW and MODPATH. The dispersed plume from the same source location simulated using MOC3D can be interpreted as the probability that the contaminant will be detected at each location within 20 years. The dispersion coefficient approximately accounts for the uncertainty in predicted flowpaths caused by imperfect knowledge of aquifer properties, recharge rates, stream levels, and other factors. Although the monitoring wells in the example do not intercept the deterministic flowpath from MOD-
PATH, the probabilistic simulation from MOC3D shows that one monitoring well has a significant chance of detecting the actual unknown contaminant migration. Detailed field characterization can reduce uncertainties and sharpen the contaminant occurrence probability map. Similar approaches can be used to delineate probabilistic source areas (capture zones) for pumping wells using MOC3D.

\section{ATTENUATION OF CONTAMINANTS IN AQUIFERS HAVING SPATIALLY VARIABLE GEOCHEMISTRY}

Natural attenuation refers to ongoing hydrologic, geochemical, and biologic processes that mitigate contaminant spread in aquifers. For example, many components of gasoline are known to dissipate in aquifers because of biodegradation; these organic chemicals are converted to other organics and ultimately to carbon dioxide and water. The rates of these reactions, however, may or may not be sufficient to limit spread, depending on the ground-water velocity and site-specific biogeochemistry (for example, Landmeyer and others, 1998).

Many biodegradation reactions are sensitive to redox (oxidation-reduction) geochemical conditions that can vary with time and over short distances. Generally, simulation of reactive solute transport requires many biogeochemical parameters and substantial computations to account for complex solute interactions. An alternative, approximate approach that requires fewer input parameters and less computer time is to simulate the transport of each solute separately and to account for solute interactions by adjusting decay and growth/loss rates. Recent extensions to MOC3D (Goode, 1999) allow reaction-rate coefficients to vary with time and to vary by model cell.

Although this approach cannot account for all solute interactions that may be important for natural attenuation, this approximation may be appropriate for some field situations, especially where site-specific information about reaction kinetics is incomplete or not available.

An illustrative simulation uses time- and space-varying decay coefficients to approximate biodegradation of benzene at the Laurel Bay, S.C., research site (Landmeyer and others, 1998). Benzene attenuation depends on decay rates that are generally higher in aerobic (oxygen rich) zones and lower in anaerobic (zero oxygen) zones (fig. 2). Furthermore, anaerobic biodegradation rates are dependent on the specific terminal-electron-acceptingprocess (TEAP) controlling the redox state. Methyl tert-butyl ether (MTBE) is another gasoline-derived contaminant
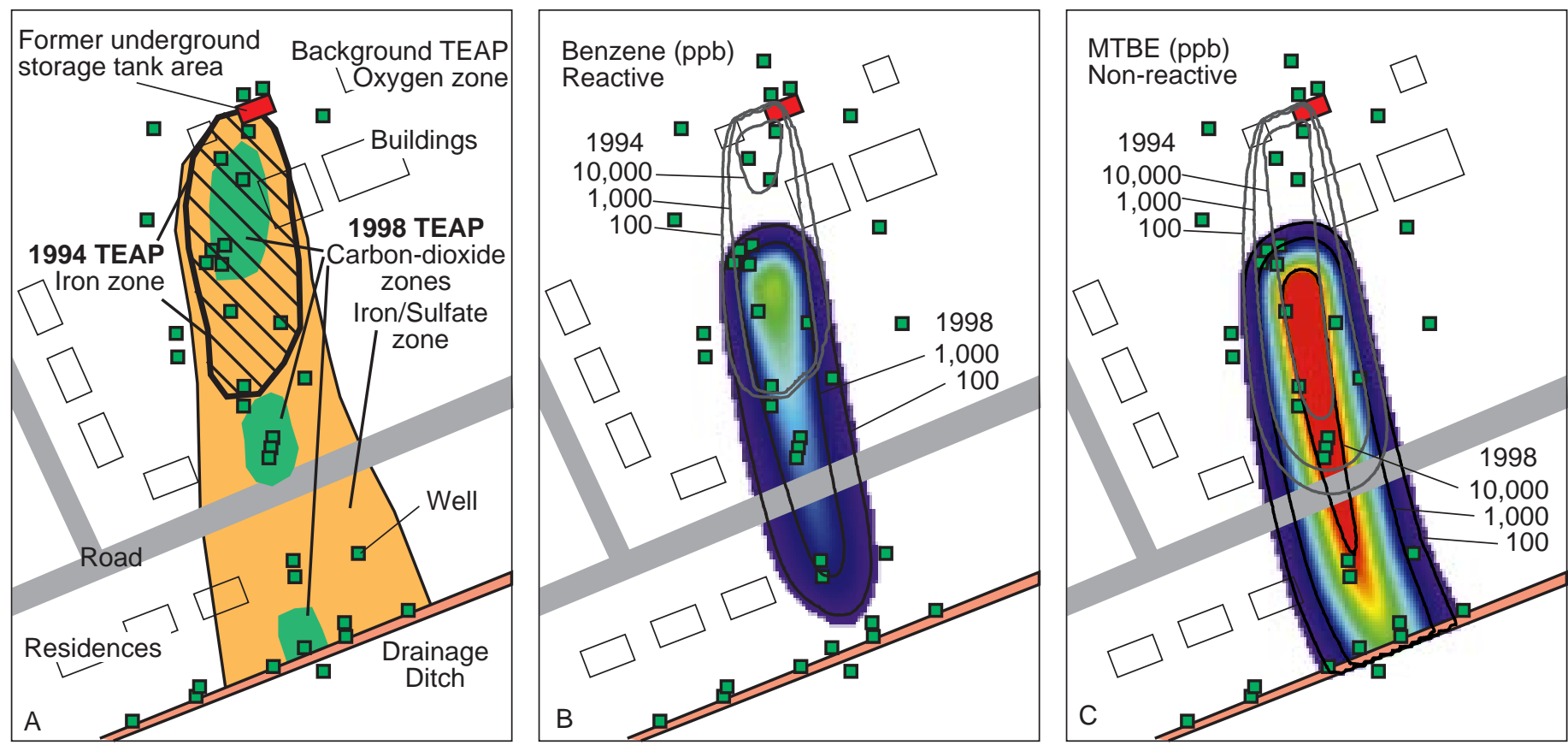

Figure 2. MOC3D simulation of benzene and MTBE at the Laurel Bay, S.C., research site, based on field and lab data of Landmeyer and others (1998): (A) Location map with anaerobic terminal-electron-accepting-process (TEAP) zones in 1994 (hatched) and 1998 (colors); (B) Benzene in 1994 and 1998; (C) MTBE in 1994 and 1998. In (B) and (C), the 1998 color maps range from 0 to 10,000 parts per billion (ppb); contours show 100,1,000, and 10,000 ppb concentration levels. 
in ground water at this site, but it is essentially non-reactive during transport. The source concentrations are the same for both contaminants, so differences in the simulated concentrations are caused by differences in the decay coefficients: 0.0 for MTBE and varying from 0.0005 to 0.1 per day for benzene, depending on the redox conditions. Fast aerobic degradation is taking place outside the illustrated anaerobic TEAP zones, except at early time when the microbes are assumed to be in low concentrations. As oxygen is consumed, the area of anaerobic redox conditions spreads, as illustrated by the differences between the 1994 and 1998 zones (fig. 2a). Degradation rates are lower in the iron and sulfate reduction zones than in the aerobic zone and are lowest in the methanogenic (carbon dioxide) TEAP zones. MOC3D simulation with temporally and spatially varying decay coefficients realistically approximates the extent of benzene migration observed at the site, which can not be simulated successfully by use of a single decay coefficient.

\section{DOUBLE-POROSITY EXCHANGE: MATRIX DIFFUSION IN Fractured ROCK}

A recent extension to $M O C 3 \mathrm{D}$ (Goode, 1999) incorporates the effects of diffusive exchange between mobile and immobile water on solute concentrations. In fractured-rock systems, such as crystalline rocks at the USGS Mirror Lake, N.H., research site (Shapiro and others, 1995), diffusive exchange between flowing water in open fractures and immobile (or nearly immobile) water in partly filled fractures and rock matrix ("matrix diffusion") may appreciably alter contaminant concentrations. The effective porosity of the open fractures corresponds to the aperture or separation of the fracture and is typically much less than 1 percent of the aquifer vol-

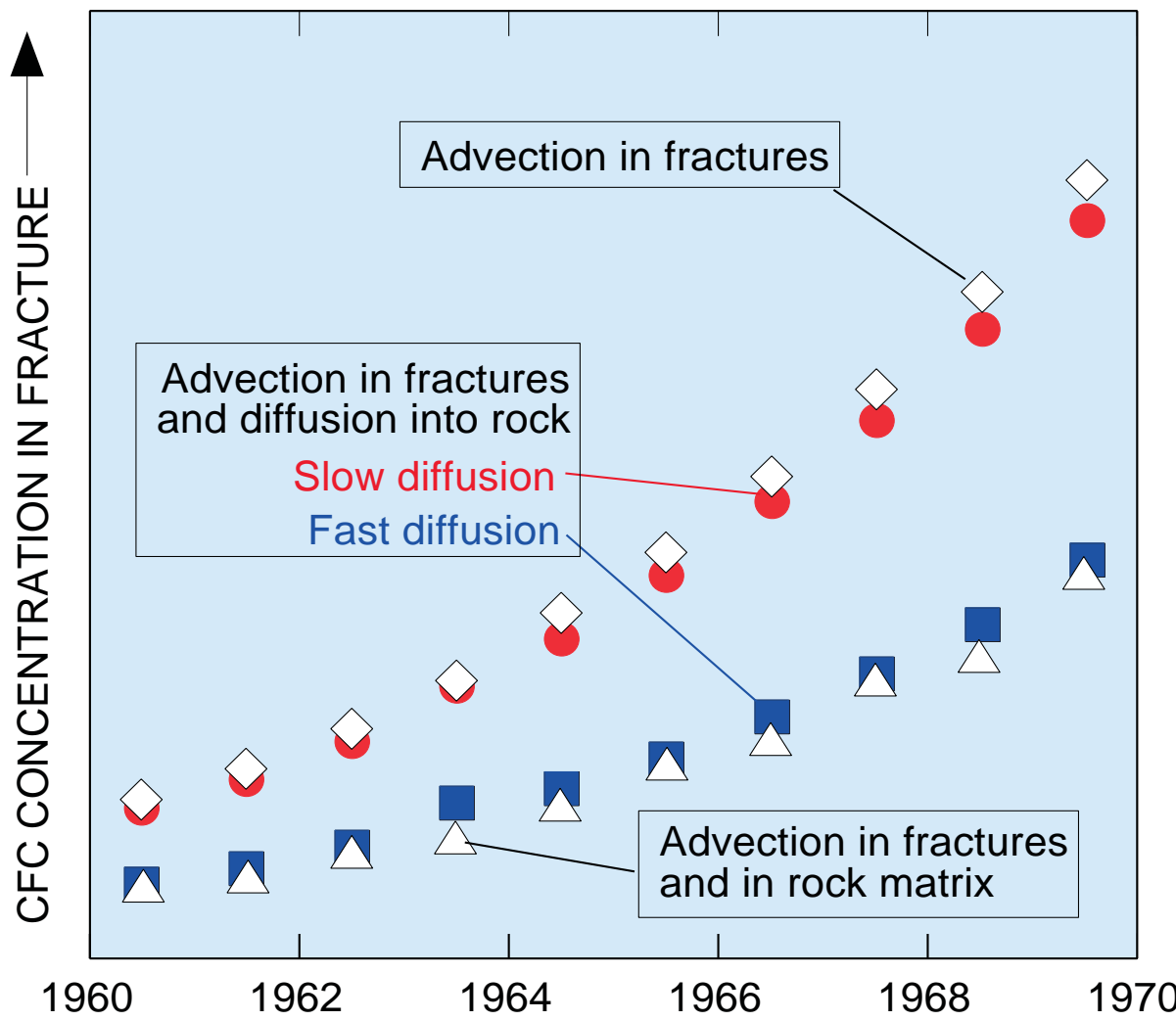

Figure 3. Comparison of simulated CFC build up in fractured rock at the USGS Mirror Lake, N.H., research site for different rates of solute diffusion from water flowing in the open fractures into immobile water within filled fractures and rock matrix. The rate at which CFC concentrations increase depends not only on the advective traveltime and effective porosity but also on the rate of matrix diffusion.

ume. Although it does not contribute appreciably to ground-water flow, the porosity within the low-permeability rock matrix and partly filled fractures may be a substantial reservoir for solute mass.

The double-porosity exchange capabilities of MOC3D can be used to quantify the effects of matrix diffusion on chlorofluorocarbon (CFC) concentrations (or other, higher-concentration contaminants) in fractured-rock aquifers. Increasing atmospheric CFC concentrations have resulted in increasing concentrations of CFC's in groundwater recharge. The rate at which CFC's in ground water increase depends on transport properties such as flow rates and effective porosity. Hence, comparison of simulated and measured CFC concentrations can help identify these transport properties. If the rate of matrix diffusion from the water flowing in the open fractures into low-permeability zones is fast enough, the apparent effective porosity of the aquifer, based on CFC concentrations, is that of the open fractures and the immobile zones combined (fig. 3). As illustrated, matrix diffusion can reduce contaminant concentrations in fractured-rock aquifers in which the effective porosity of the fractures is small and the rate of diffusive exchange is as fast, or faster, than transport in the fractures.

\section{ADDITIONAL SITE STUDIES INFORMATION}

Additional information on contaminant attenuation, including research at Mirror Lake, N.H., and Laurel Bay, S.C., can be obtained at the USGS Toxic Substances Hydrology Program Web site at http://toxics.usgs.gov/toxics. Project descriptions and publication lists for the USGS Water Resources Division National Research Program are available on the Web at http://wwwrvares.er.usgs.gov/nrp/nrp.html. Information on local studies and groundwater model applications can be obtained from USGS state representatives at http://www.usgs.gov. 


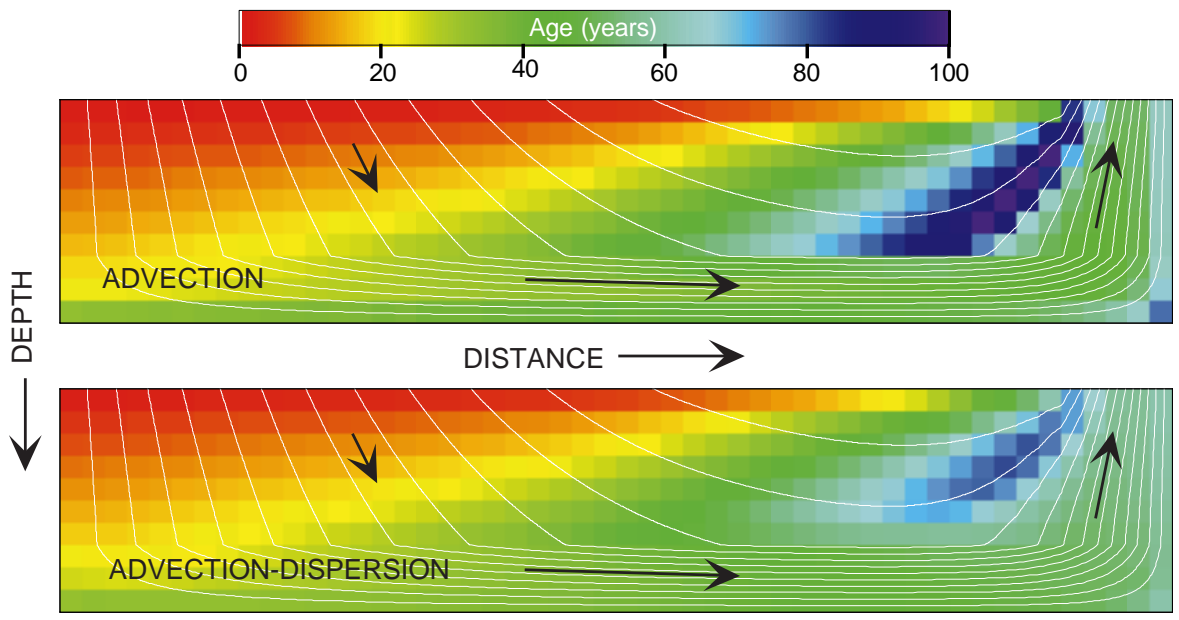

Figure 4. Streamlines and ground-water age distributions with and without dispersion in a regional layered aquifer system.

\section{EFFECTS OF DISPERSION ON GROUND-WATER AGE}

A convenient framework for analyzing and comparing environmental tracer information is through groundwater age, defined as the time since the water was isolated from the atmosphere. Apparent ages determined at locations distributed in an aquifer can be compared to advective traveltimes computed by particle tracking and, therefore, can be used to help estimate hydraulic and transport properties. However, this approach cannot account for possible modification of the age distribution by other transport processes such as dispersion, mixing, and matrix diffusion.

\section{References Cited}

Goode, D.J., 1999, Age, double-porosity, and simple reaction modifications for the MOC3D ground-water transport model: U.S. Geological Survey WaterResources Investigations Report 99-4041, 34 p.

Harbaugh, A.W., and McDonald, M.G., 1996, User's documentation for MODFLOW-96, an update to the U.S. Geological Survey modular finite-difference groundwater flow model: U.S. Geological Survey Open-File Report 96-485, $56 \mathrm{p}$

Hornberger, G.Z., and Konikow, L.F., 1998, Addition of MOC3D solute-transport model capability to the U.S. Geological Survey MODFLOW-96 graphicaluser interface using Argus Open Numerical Environments: U.S. Geological Survey Open-File Report 98188, $30 \mathrm{p}$.

Kipp, K.L., Jr., Konikow, L.F., and Hornberger, G.Z., 1998, An implicit dispersive transport algorithm for the U.S. Geological Survey MOC3D solute-transport model: U.S. Geological Survey Water-Resources Investigations Report 98-4234, 54 p.
Ground-water age can be simulated directly in MOC3D by use of a solute-transport equation having an internal source of unit strength (for example, 1 year per year) corresponding to the rate of aging (Goode, 1999). Because this method is based on a solute-transport equation, effects of dispersion, mixing, and other processes are easily simulated. The output from the model, which is usually concentration, is in this case the age of ground water at all locations in the aquifer (fig. 4). Age for the case of advection alone also can be simulated in MOC3D because the method-of-characteristics approach is well-suited to cases without dispersion, in contrast to traditional finite-difference and finite-element models.

-Daniel J. Goode

Konikow, L.F., Goode, D.J., and Hornberger, G.Z., 1996, A three-dimensional method-of-characteristics solute-transport model (MOC3D): U.S. Geological Survey Water-Resources Investigations Report 96-4267, $87 \mathrm{p}$

Landmeyer, J.E., Chapelle, F.H., Bradley, P.M., Pankow, J.F., Church, C.D., and Tratnyek, P.G., 1998, Fate of MTBE relative to benzene in a gasoline-contaminated aquifer (1993-98): Ground Water Monitoring and Remediation, v. 18, no. 4, p. 93-102.

Pollock, D.W., 1994, User's guide for MODPATH/MODPATH-PLOT, version 3: A particle tracking postprocessing package for MODFLOW, the U.S. Geological Survey finite-difference ground-water flow model: U.S. Geological Survey Open-File Report 94$464,234 \mathrm{p}$.

Shapiro, A.M., Hsieh, P.A., and Winter, T.C., 1995, The Mirror Lake fractured-rock research site-A multidisciplinary research effort in characterizing groundwater flow and chemical transport in fractured rock: U.S. Geological Survey Fact Sheet FS-138-95, 2 p.
MOdEL COMPATIBILITY AND AVAILABILITY

MOC3D is written in Fortran 77 and runs on a variety of computer platforms, including personal computers. Documentation of MOC3D is available in a series of USGS reports (Konikow and others, 1996; Kipp and others, 1998; Goode, 1999). The documentation, along with the source code and several executable versions of the model, can be accessed on the Web at

\section{http://water.usgs.gov/ software/moc3d.html}

or

\section{http://simul8.er.usgs.gov}

Future extensions to MOC3D will be posted as they become available. These Web sites also have links to related USGS ground-water modeling programs, including a graphical user-interface for MODFLOW and MOC3D (Hornberger and Konikow, 1998).

The USGS Office of Ground Water Web site at

\section{http://water.usgs.gov/public/ogw}

includes information on many tools for quantitative hydrogeologic analyses.

\section{FOR MORE INFORMATION}

Additional earth science information can be found by accessing the USGS Home Page at

\section{http://www.usgs.gov}

For information on all USGS products and services, call 1.888.ASK.USGS

Fax: 703.648 .5548

email: esic@usgs.gov 